\title{
Head injuries in children: a prospective five year follow-up
}

\author{
H. KLONOFF, M. D. LOW, AND C. CLARK
}

From the Department of Psychiatry and Medicine (Neurology), University of British Columbia, Vancouver, British Columbia, Canada

SUMMARY A five year follow-up study was conducted with two groups of head-injured children, 131 younger than 9 years old at time of injury and 100 older than 9 years. The four aspects studied were neuropsychological function, neurological status, EEG status, and school progress. There was an extended recovery process over time, as well as evidence of a differential rate of recovery for the four aspects measured.

Our understanding of the natural history of head injuries in children can best be increased by prospective, long-term, multidimensional studies. The paucity of such clinical studies has been commented on (Black et al., 1971; Lishman, 1973; Klonoff and Paris, 1974). A study which would add to our knowledge of the head-injured child should be broad in scope. Firstly, it should include: antecedent factorsconstitutional predisposition, premorbid personality, age, sex, environmental hazards; circumstances at time of head injury - the nature and extent of injury, resilience of the neural apparatus in childhood, the nature of intervention and management during the acute and postacute phases; and consequence factors - the effect of brain damage on general adaptation and maturation, on the development of post-traumatic epilepsy, effect on education, transaction with family, and the role of compensation and litigation. Secondly, it should encompass a variety of clinical examinations including neurological, electroencephalographic, and psychological. Thirdly, the study should address itself to the interaction of effects, namely, the differentiation of immediate from short-term or long-term effects, and the nature and course of reconstitution.

This study accordingly set out to investigate prospectively a head-injured group of children from the time of trauma (hospitalisation) to the fifth year after trauma, within the context of the model noted above. Previous publications have reported our methods, and the immediate and short-term effects

\footnotetext{
Address for reprint requests: Dr H. Klonoff, Division of Psychology Department of Psychiatry, University of British Columbia, 2255 Wesbrook Crescent, Vancouver, BC, Canada, V6T 1W5. Accepted 23 June 1977
}

(Klonoff et al., 1969; Klonoff, 1971; Klonoff and Low, 1974; Klonoff and Paris, 1974); this publication deals with the long-term effects, with particular emphasis on predicting outcome.

\section{Method}

\section{PROJECT SAMPLE}

The clinical sample consisted of children aged between 2.7 and 15.9 years at time of head injury. The children were examined during initial hospital admission and each year for five consecutive years after head injury. The sample comprised consecutive admissions with head injury to either the Health Centre for Children or St Paul's Hospital in Vancouver, British Columbia. The sample was divided into two groups: younger children (less than 9 years old) - initially 131 children, after five years 78; and older children (more than 9 years old)-initially 100 , after five years 39 . Initially for the younger group, there were 80 males and 51 females with a mean age of 5.87 years $(\mathrm{SD}=1.76)$ and a $52 \%$ skull fracture rate. For the older group, there were 67 males and 33 females with a mean age of 11.53 years $(S D=1.81)$ and $32 \%$ fractures. Within the two groups, no discernible differences were found on these variables between the original and the followed groups. As previous studies (Klonoff et al., 1969; Klonoff and Low, 1974) have indicated that with the examination procedures outlined below, there are no sex differences, sex was not included in the analysis.

\section{EXAMINATION PROCEDURE}

Neuropsychological test battery

The neuropsychological examination included the 
Reitan-Indiana Neuropsychological Test Battery for Children, two of Benton's tests, a lateral dominance test, the Stanford Binet, form L-M for children under 5 years of age, or the Wechsler Intelligence Scale for Children (WISC) for those aged over 5 years, and for children over 9 years the Kløve Motor Steadiness Battery. Thus, for the younger group complete data for the six examinations were obtained on 18 tests or 32 variables, while for the older group on 23 tests or 48 variables. Test construction, scoring, and normative data have been reported by Benton (1959), Knights (1966), Klonoff et al. (1969), Klonoff and Low (1974), and Reitan (1974). For the neuropsychological test battery, each subject was matched on age (within three months) and sex with a normal control. These control subjects referred by six paediatricians in the Vancouver area were classed as normal by four criteria: no neurological deficit; no physical anomalies; no profound signs of emotional disturbance; and normal school progress for those children attending school. The two head-injured groups and their matched controls were compared using an analysis of variance and orthogonal contrasts for each variable at each yearly examination.

\section{Neurological examination}

During initial hospital admission, a neurological assessment of degree of head injury was assigned to each child based on the following schema: minor (1) - suspected but not proven loss of consciousness, no evidence of concussion; mild (2)-suspected but not proven loss of consciousness, concussion (lethargy, vomiting, drowsiness, contusion, nausea, dizziness); moderate (3)-loss of consciousness for less than $5 \mathrm{~min}$, concussion; severe (4)-loss of consciousness for 5-30 min, concussion or skull fracture; and serious (5) - loss of consciousness for more than $30 \mathrm{~min}$, concussion or skull fracture (depressed or compound or both), other sequelae (psychosis, aphasia, etc.). For the subsequent assessments, each child was examined for: complaints resulting from the head injury (for example, headaches); sequelae (that is, neurological, personality, subjective, or learning); and school progress. Again these data were analysed with respect to the two cohort groups (younger and older) and these groups were compared with the original samples.

\section{EEG}

Initial and repeat EEG records were obtained from each head-injured child during initial hospital admission and then once a year for five consecutive years. Hyperventilation for $3 \mathrm{~min}$ and sleep (induced by chloral hydrate) were used routinely for activation. Recording techniques included the application of 19 scalp electrodes plus two ear electrodes in the International $10-20$ positions. Both referential (ear) and bipolar montages were used, awake and asleep. All tracings were interpreted by the same electroencephalographer (MDL). Besides describing the qualitative features of the records, he assigned each a global rating of normal (1), borderline (1.5), minimally abnormal (2), moderately abnormal (3), or markedly abnormal (4). The criteria for this are fully described by Klonoff and Low (1974). These data were analysed using children who were seen on six occasions and then the followed and original groups were compared.

\section{PREDICTION FOR RESIDUAL EFFECTS}

For each of the three examinations additional analyses were done with variables obtained during initial hospital admission, in order to ascertain if a model of prediction could be developed. Specifically, these variables were: Full Scale IQ, age (in years), unconsciousness (duration in minutes), retrograde amnesia (duration in minutes), anterograde amnesia (duration in minutes), gestation period (in weeks), EEG rating, and neurological rating.

\section{Results}

\section{NEUROPSYCHOLOGICAL FINDINGS}

Tables 1 and 2 summarise the results of the analyses of variance on the neuropsychological variables for the younger and older head-injured groups and their respective matched controls. The 'between-groups' difference column indicates whether the two groups are different over all years combined. Of the possible $32 \mathrm{~F}$ values, 29 were significant for the younger group, while for the older group 43 of the $48 \mathrm{~F}$ values were significant. The 'between-year' differences show whether there is a change in performance with time regardless of membership in either the head-injured or control groups. For the younger group, 31 of these differences were significant, while for the older group 43 were significant. These findings indicated improved performance with repeated exposure to the test battery (learning) or increasing age (maturation), or both. The 'groups $\times$ year' interaction term indicates whether there are differential rates of learning or performance between the two groups with repeated exposure to the test battery. For the younger group, 18 of these tests were significant, while for the older group 21 were significant.

In the six remaining columns (that is, 'contrasts') the results for the yearly group contrasts are recorded. These contrasts indicated whether the head-injured were different at specific examinations compared with the normal groups. For the younger group, the total numbers of significant differences were as follows: 
Table 1 Comparison of younger head-injured patients with matched controls on neuropsychological variables-analysis of variance

\begin{tabular}{|c|c|c|c|c|c|c|c|c|c|}
\hline \multirow[b]{2}{*}{ Variables } & \multirow[b]{2}{*}{$\begin{array}{l}\text { Between- } \\
\text { group } \\
\text { difference } \\
n^{*}\end{array}$} & \multirow[b]{2}{*}{$\begin{array}{l}\text { Between } \\
\text { years } \\
\text { difference } \\
n^{*}\end{array}$} & \multirow[b]{2}{*}{$\begin{array}{l}\text { Groups } \\
\times \text { years } \\
\text { inter- } \\
\text { action } \\
n^{*}\end{array}$} & \multicolumn{6}{|c|}{ Contrasts } \\
\hline & & & & $\begin{array}{l}\text { Time of } \\
\text { trauma } \\
n=131\end{array}$ & $\begin{array}{l}\text { One } \\
\text { year } \\
\text { later } \\
n=113\end{array}$ & $\begin{array}{l}\text { Two } \\
\text { years } \\
\text { later } \\
n=97\end{array}$ & $\begin{array}{l}\text { Three } \\
\text { years } \\
\text { later } \\
n=86\end{array}$ & $\begin{array}{l}\text { Four } \\
\text { years } \\
\text { later } \\
n=78\end{array}$ & $\begin{array}{l}\text { Five } \\
\text { years } \\
\text { later } \\
n=75\end{array}$ \\
\hline 1 Category test (err.) & $26.62 \tau_{1}$ & 1.87 & 0.35 & $4.97 \ddagger$ & $5.14 \ddagger$ & $7.76 \|$ & $3.98 \|$ & $6.63 \|$ & 0.95 \\
\hline 2 Tapping-dom. (corr.) & 3.39 & $183.53 \top$ & 0.81 & 7.05I & 0.71 & 0.02 & 0.81 & 0.23 & 0.01 \\
\hline Tapping - non-dom. (corr.) & $5.56 \S$ & $158.31 \%$ & 0.44 & $3.87 \ddagger$ & 1.49 & 1.95 & 1.73 & 0.10 & 0.01 \\
\hline 3 Speech perception (err.) & $31.04 \tau^{\top}$ & $91.71 \%$ & $3.20 \|$ & 30.79 & $20.17 \%$ & $3.98 \dagger$ & 0.80 & 0.61 & 1.07 \\
\hline 4 Trail making-A (time) & $33.50 \%$ & $75.40 \uparrow$ & 1.30 & & 11.45 & 17.459 & 2.64 & 1.29 & 1.22 \\
\hline Trail making-B (time) & $23.78 \%$ & $51.17 \pi$ & $3.50 \|$ & $\dagger$ & $4.60 \dagger$ & 24.769 & $4.11 \ddagger$ & $5.29+$ & 0.56 \\
\hline Trail making - total (time) & 38.40 & 72.209 & $3.16 \|$ & & $3.99 \ddagger$ & $35.83^{\circ}$ & $5.12 \ddagger$ & $5.80 \S$ & 1.29 \\
\hline 5 Matching figures (time) & $4.58+$ & $69.65 \uparrow$ & 1.56 & $7.67 \|$ & 7.00 & 0.40 & 0.00 & 0.00 & 0.00 \\
\hline Matching figures (err.) & $4.93+$ & $52.29 \top$ & 1.79 & $13.29 ף$ & 2.86 & 0.66 & 0.00 & 0.06 & 0.05 \\
\hline 6 Matching Vs (time) & $10.94 \|$ & $64.69 \%$ & $2.43 \ddagger$ & $20.10 \ddagger$ & 3.00 & 1.15 & 3.25 & 0.12 & 0.26 \\
\hline Matching Vs (err.) & $19.43 \pi$ & $81.14^{\top}$ & $2.40_{+}^{+}$ & 9.72\| & $20.93 \pi$ & $5.38 \S$ & 0.07 & 0.08 & 1.12 \\
\hline 7 Star (corr.) & 13.059 & $53.67^{\circ}$ & $3.90 \|$ & $31.26 \mathrm{~T}$ & $7.33 \|$ & 0.09 & 0.11 & 0.17 & 0.28 \\
\hline 8 Concentric squares (corr.) & $15.34 \pi$ & $84.21 \%$ & $7.03 \uparrow$ & $50.82 \tau$ & 2.78 & $6.35 \S$ & 0.03 & 0.17 & 0.04 \\
\hline 9 Progressive figures (time) & $38.85 \pi$ & $50.65 \%$ & $8.53 \%$ & $24.81 \tau$ & 66.959 & 4.71t & 0.26 & 0.32 & 0.11 \\
\hline 10 Colour form (time) & $15.16 \uparrow$ & 67.129 & $3.30 \|$ & $11.63 \uparrow$ & 24.479 & 1.68 & 0.07 & 0.14 & 0.04 \\
\hline Colour form (err.) & $24.40^{\top}$ & $40.95-$ & $3.75 \mid i$ & $22.60 \%$ & $22.67 \pi$ & $7.24 \|$ & 0.51 & 0.02 & 0.04 \\
\hline 11 Target test (corr.) & $19.97 \Phi$ & $129.97 \top$ & 1.01 & $4.67+$ & $15.23 \%$ & $5.34 \S$ & 1.57 & 0.75 & 0.93 \\
\hline 12 Marching test-dom. (time) & $11.77 \pi$ & $97.31 \%$ & 1.70 & 17.55 & 2.32 & $3.93 \div$ & 0.13 & 0.34 & 0.33 \\
\hline Marching test-dom. (err.) & $8.16 \|$ & $38.04 \uparrow$ & 3.43 & $26.86^{\circ}$ & 2.93 & 0.13 & 0.01 & 0.21 & 0.01 \\
\hline Marching test-non-dom. (time) & $13.44 \pi$ & $107.20 \uparrow$ & 1.41 & $16.88^{\circ}$ & 2.89 & 3.68 & 0.42 & 0.45 & 0.38 \\
\hline Marching test-non-dom. (err.) & $29.03 \%$ & 33.26 & $4.30 \%$ & $48.29 \div$ & $5.84 \S$ & 3.31 & 1.11 & 1.58 & 0.65 \\
\hline 13 TPT-dom. (time) & $9.25 \|$ & 113.679 & $8.55 \uparrow$ & $53.42 \pi$ & $4.80+$ & 1.13 & 0.07 & 0.05 & 0.11 \\
\hline TPT-non-dom. (time) & 2.59 & 116.189 & $2.30 \pm$ & $15.85 \%$ & 0.36 & 0.03 & 0.00 & 0.00 & 0.02 \\
\hline TPT_-both (time) & $13.61 \%$ & 120.91 T & $12.05 \uparrow$ & $83.58 \top$ & 0.20 & 0.25 & 0.19 & 0.05 & 0.06 \\
\hline TPT-total (time) & $13.87 \%$ & $146.19 \uparrow$ & $14.85 \uparrow$ & $95.11 \uparrow$ & $4.05 \ddagger$ & 1.23 & 0.01 & 0.03 & 0.00 \\
\hline TPT-memory (corr.) & 2.72 & 106.02 ग & 0.39 & 2.86 & 0.01 & 1.21 & 1.02 & 0.19 & 0.00 \\
\hline TPT-location (corr.) & $11.41 \uparrow$ & 82.36 & 1.02 & 9.95 & 4.47 & 1.40 & $3.81 \ddagger$ & 0.01 & 0.12 \\
\hline 14 Matching pictures (corr.) & $11.07 \|$ & 99.10 ศ & 0.79 & $10.54 \|$ & $3.92+$ & 0.78 & 0.16 & 1.37 & 0.89 \\
\hline 15 Sound recognition & $34.73 \%$ & $40.24 \pi$ & $3.88 \|$ & $45.22 థ$ & $13.46 \pi$ & 2.89 & 1.40 & 1.22 & 1.44 \\
\hline 16 Right left orientation (corr.) & $19.12 \%$ & $35.09 \top$ & 1.71 & $17.19 \%$ & $7.99 \|$ & $5.17 \ddagger$ & 0.61 & 2.42 & 0.01 \\
\hline 17 Lateral dominance (corr.) & 7.26 & 22.879 & $2.47_{+}^{+}$ & $19.66 \%$ & 0.50 & 0.93 & 0.22 & 1.09 & 0.31 \\
\hline 18 Full IQ & 194.10 & $14.03 \tau_{i}$ & 0.84 & 67.599 & $52.90 \%$ & $28.21 \top$ & $25.80 \%$ & $23.23 \mathrm{I}$ & 19.02 \\
\hline Total number of significant differenc & 29 & 31 & 18 & 28 & 20 & 13 & 5 & 4 & 1 \\
\hline
\end{tabular}

*The total number used was 580 . In the analysis of variance, comparisons between groups are based on the respective weights of the groups. tContrast deleted as a number of subjects were too young to complete the test.

$\$ \mathrm{P}<0.05 \quad \S \mathrm{P}<0.02 \quad \| \mathrm{P}<0.01 \quad$ IP $<0.001$.

28 during initial hospital admission; 20 one year later; 13 two years later; five three years later; four four years later; and one five years later. For the older group, the number of significant differences for specific examinations were as follows: 42 during initial hospital admission; 31 one year later; 15 two years later; 12 three years later; eight four years later; and six five years later.

To supplement the group data, a further analysis was done to determine if there existed a subgroup within the head injury groups which was different both from the normal controls and from the majority of the head-injured children. For both the younger and older groups, the within-group variances for each variable (IQ excluded) were compared in order to determine if there were any differences in the specific variable distributions between the normal children and head-injured groups on the last re-examination.
From this analysis, 11 variables had a ratio of head injured to normal variance greater than three.

Each head-injured and normal child was assigned a score for these variables based on the scores of a normal sample of 158 children who had been classed by age and had done the test battery six times. The scores were assigned in terms of standard deviations above and below the mean (that is, $\mathbf{0}= \pm 1 \mathrm{SD}, \pm \mathbf{1}= \pm \mathbf{1}$ to $\pm \mathbf{2} \mathrm{SD}, \pm \mathbf{2}=$ greater than \pm 2 SD). Thus, the resulting scoring schema had a range from -22 to 22 . If the head-injured and normal groups were truly equivalent, the resulting distributions of scores for each group should be more or less the same, with a mean near zero. These results (Table 3) clearly indicate that there was a subsample of head-injured children who were different both from the normals and from the majority of headinjured children. Empirically, $23.7 \%$ of the head- 
Table 2 Comparison of older head-injured patients with matched controls on neuropsychological variables—analysis of variance

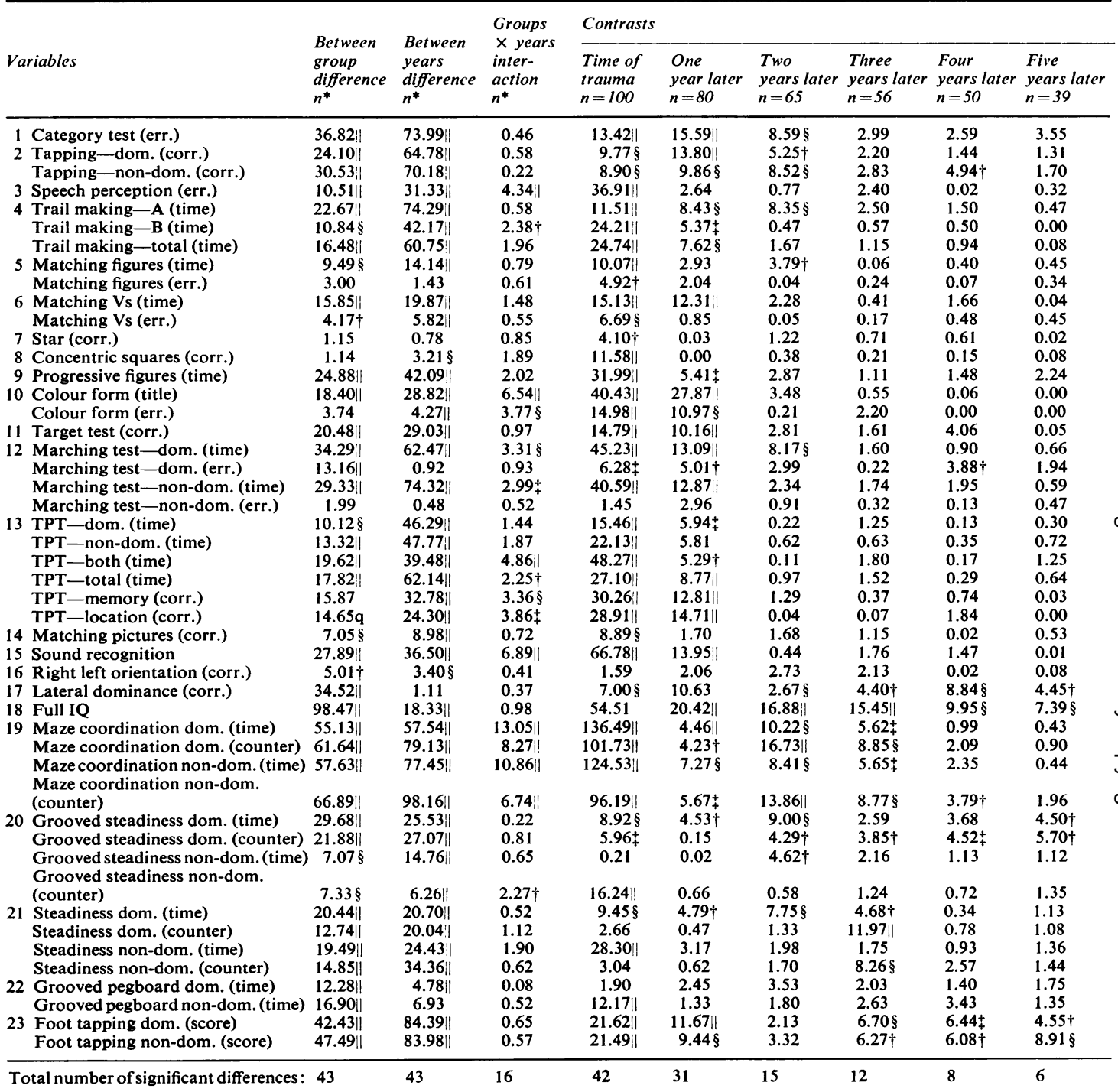

*The total number used was 390 . In the analysis of variance, comparisons between groups are based on the respective weights of the groups.

$\dagger \mathrm{P}<0.05 \quad \ddagger \mathrm{P}<0.01 \quad \S \mathrm{P}<0.01 \quad \| \mathrm{P}<0.001$

injured children fell outside the cutoff point of -5 (that is, performance was impaired) while only $4.4 \%$ of the normal children were beyond this cutoff point.

Analysis of variance on IQ status over the six examinations provides cross-validation regarding the existence of subgroups within the head-injured sample. The IQ scores for three groups-normal children (114), head-injured children with no discernible evidence of residual neuropsychological effects (87), and head-injured children with evidence of residual neuropsychological effects (27)-were compared during initial hospital admission and five years later, between and within groups (Table 4). A Tukey's multiple comparison technique indicated that: (1) all three groups were significantly different 
Table 3 Distribution of the summed deviation sources

\begin{tabular}{|c|c|c|c|c|c|c|}
\hline \multirow{2}{*}{ Distribution } & \multicolumn{2}{|c|}{ Older $(n=39)$} & \multicolumn{2}{|c|}{ Younger $(n=75)$} & \multicolumn{2}{|c|}{ Total $(n=114)$} \\
\hline & Normals & Head-injured & Normal & Head-injured & Normal & Head-injured \\
\hline Worst performance $(<-5)$ & 1 & 8 & 4 & 19 & 5 & 27 \\
\hline Cutoff $(-5$ to 5$)$ & 34 & 31 & 70 & 55 & 104 & 86 \\
\hline Best performance $(>5)$ & 4 & 0 & 1 & 1 & 1 & 1 \\
\hline Range & -7 to 8 & -14 to 5 & -9 to 6 & -14 to 7 & -9 to 8 & -14 to 7 \\
\hline
\end{tabular}

Table 4 Full scale IQ means for three groups*

\begin{tabular}{llll}
\hline $\begin{array}{l}\text { Examination } \\
\text { points }\end{array}$ & Normal & $\begin{array}{l}\text { Head-injured } \\
\text { no residual } \\
(n=87)\end{array}$ & $\begin{array}{l}\text { Head-injured } \\
\text { residual } \\
(n=27)\end{array}$ \\
\hline Time of trauma & 114.8 & 105.7 & 92.3 \\
Five years later & 120.4 & 116.4 & 98.9 \\
\hline
\end{tabular}

${ }^{*}$ F-values for the ANOVA were: between groups $\mathrm{F}=97.9, \mathrm{P}<0.001$; between examinations $\mathrm{F}=41.8$, $P<0.001$; group by examination $F=3.05, P<0.05$.

during initial hospital admission; (2) the headinjured group with no evidence of residual effects had a significant increase in IQ from initial hospital admission to the fifth follow-up examination and, five years later, this group was no longer different from the normal controls; but (3) both this group and normal children were significantly different from the head-injured group with evidence of residual neuropsychological effects on the fifth follow-up. These comparisons indicated that IQ should be regarded as a dependent variable in the assessment of head injury effects.

In summary, these analyses indicated that the majority $(76.3 \%)$ of the head-injured patients (younger and older) made a marked recovery over time. Moreover, this recovery pattern was extended over the whole five year period of follow-up examinations because significant contrasts were still found between the fourth and fifth follow-ups.

With respect to developing a model of prediction for residual neuropsychological effects, a discriminant analysis was done on the eight variables recorded during initial hospital admission with the two identified subgroups of head-injured children (those with no positive signs (87) and those with positive signs (27)) (Table 5). The discriminations were consistently high and the overall discrimination rate was $84.2 \%$.

\section{NEUROLOGICAL FINDINGS}

For the reported complaints whether present at the examination or not (Table 6), the two cohort groups were obviously not different either from each other or from the original sample one year after head injury. Both groups had fewer complaints on the fifth follow-up than on the first. However, only for the older group did the number of children with complaints decrease significantly $\left(\chi^{2}=4.18, \mathrm{P}<0.05\right)$. The specific complaint which best illustrates this differential pattern was headaches. Between the first and the fifth follow-up the incidence of headaches decreased slightly for the younger group (24\% to $19.2 \%)$ and substantially for the older group $(28 \%$ to $10 \%, \chi^{2}=2.97, \mathrm{P}<0.10$ ). A similar trend was found for complaints in the personality area. Variables which showed similar decline for both groups were learning, mood, fatigue, and voluntary muscles.

For the sequelae data which comprised symptoms present at examination (Table 7), the cohort groups and original groups' comparisons on the first followup examination indicated that the older groups were equivalent $(46 \%$ to $44 \%$ ) while the younger cohort exhibited more sequelae than the original younger group ( $45 \%$ to $36 \%$ ). However, the assessed sequelae for the younger and older cohort groups were equivalent on the first follow-up examination ( $45 \%$ to $46 \%$ and 0.76 to 0.77 sequelae per subject, respectively). When the two groups were compared on these two measures five years after initial hospital admission, $38 \%$ of the younger group still had sequelae (mean number per subject $=0.62$ ) while $31 \%$ of the older

Table 5 Discriminant analysis-neuropsychological and EEG

\begin{tabular}{|c|c|c|c|c|c|c|c|c|c|c|}
\hline & \multirow[b]{2}{*}{ Number } & \multicolumn{4}{|c|}{ Neuropsychological } & \multirow[b]{2}{*}{ Number } & \multicolumn{4}{|l|}{$E E G$} \\
\hline & & $\begin{array}{l}\text { Correct } \\
f\end{array}$ & $\%$ & $\begin{array}{l}\text { Incorrect } \\
f\end{array}$ & $\%$ & & $\begin{array}{l}\text { Correct } \\
f\end{array}$ & $\%$ & $\begin{array}{l}\text { Incorrect } \\
f\end{array}$ & $\%$ \\
\hline $\begin{array}{l}\text { Normal } \\
\text { Abnormal } \\
\text { Total }\end{array}$ & $\begin{array}{r}87 \\
27 \\
114\end{array}$ & $\begin{array}{l}77 \\
19 \\
96\end{array}$ & $\begin{array}{l}88.5 \\
70.4 \\
84.2\end{array}$ & $\begin{array}{r}10 \\
8 \\
18\end{array}$ & $\begin{array}{l}11.5 \\
29.6 \\
15.8\end{array}$ & $\begin{array}{r}104 \\
12 \\
116\end{array}$ & $\begin{array}{r}85 \\
7 \\
92\end{array}$ & $\begin{array}{l}81.7 \\
58.3 \\
79.3\end{array}$ & $\begin{array}{r}19 \\
5 \\
24\end{array}$ & $\begin{array}{l}18.3 \\
41.7 \\
20.7\end{array}$ \\
\hline
\end{tabular}


Table 6 Complaints for five year cohorts*

\begin{tabular}{|c|c|c|c|c|}
\hline & \multicolumn{2}{|c|}{ One year after } & \multicolumn{2}{|c|}{ Five years after } \\
\hline & $\begin{array}{l}<9 y r \\
(n=78)\end{array}$ & $\begin{array}{l}>9 y r \\
(n=39)\end{array}$ & $\begin{array}{l}<9 y r \\
(n=78)\end{array}$ & $\begin{array}{l}>9 y r \\
(n=39)\end{array}$ \\
\hline $\begin{array}{l}\text { Complaints: Number } \\
\text { with complaint }(f+\%) \\
\text { Mean number of } \\
\text { complaints } \dagger\end{array}$ & $\begin{array}{l}41(53 \%) \\
1.55\end{array}$ & $23(59 \%)$ & $\begin{array}{l}34(44 \%) \\
0.92\end{array}$ & $\begin{array}{l}13(33 \%) \\
0.82\end{array}$ \\
\hline $\begin{array}{l}\text { Types of complaints } \\
\text { Memory/ } \\
\text { concentration } \\
\text { Learning } \\
\text { Intellectual } \\
\text { Mood } \\
\text { Personality } \\
\text { Fatigue } \\
\text { Sleep } \\
\text { Speech } \\
\text { Tics } \\
\text { Dizziness } \\
\text { Headaches } \\
\text { Visual/auditory } \\
\text { Voluntary muscles } \\
\text { Paralysis }\end{array}$ & $\begin{array}{r}7 \\
12 \\
1 \\
12 \\
20 \\
16 \\
4 \\
2 \\
1 \\
7 \\
19 \\
7 \\
7 \\
2\end{array}$ & $\begin{array}{r}2 \\
7 \\
0 \\
5 \\
12 \\
7 \\
3 \\
0 \\
0 \\
8 \\
11 \\
3 \\
1 \\
0\end{array}$ & $\begin{array}{r}5 \\
8 \\
0 \\
6 \\
17 \\
3 \\
5 \\
1 \\
1 \\
2 \\
15 \\
2 \\
5 \\
2\end{array}$ & $\begin{array}{l}2 \\
5 \\
1 \\
3 \\
7 \\
2 \\
1 \\
0 \\
0 \\
1 \\
4 \\
4 \\
1 \\
1\end{array}$ \\
\hline
\end{tabular}

Table 7 Sequelae for five year cohort

\begin{tabular}{|c|c|c|c|c|}
\hline \multirow[t]{2}{*}{ Nature of sequelae } & \multicolumn{2}{|c|}{ One year after } & \multicolumn{2}{|c|}{ Five years after } \\
\hline & $\begin{array}{l}<9 y r \\
(n=78)\end{array}$ & $\begin{array}{l}>9 y r \\
(n=39)\end{array}$ & $\begin{array}{l}<9 y r \\
(n=78)\end{array}$ & $\begin{array}{l}>9 y r \\
(n=39)\end{array}$ \\
\hline \multirow{3}{*}{$\begin{array}{l}\text { Incidence } \\
\text { Sequelae }(f+\%) \\
\text { Equivocal }(f+\%) \\
\text { Mean number of } \\
\text { signs }\end{array}$} & & & & \\
\hline & $\begin{array}{c}35(45 \%) \\
1(1 \%)\end{array}$ & $\begin{array}{l}18(46 \%) \\
0\end{array}$ & $\begin{array}{c}30(38 \%) \\
4(5 \%)\end{array}$ & $\begin{array}{c}12(31 \%) \\
1(3 \%)\end{array}$ \\
\hline & 0.76 & 0.77 & 0.62 & 0.49 \\
\hline \multicolumn{5}{|l|}{ Areas (f) } \\
\hline Neurological & 12 & 3 & 7 & 3 \\
\hline Subjective & 19 & 12 & 19 & 5 \\
\hline Personality & 20 & 10 & 16 & 5 \\
\hline Intellectual & 8 & 5 & 6 & 6 \\
\hline
\end{tabular}

group still had sequelae (mean number $=0.49$ ). For between and within group comparisons, none were significant.

To predict the residual sequelae found during the fourth and fifth follow-up examinations, a stepwise multiple regression analysis was done on the eight variables obtained during initial hospital admission. All these variables were included ( $F$ value for deletion $=0.005$ ) and resulted in a significant multiple regression coefficient of $0.4727\left(\mathrm{~F}_{8,108}=3.96 ; \mathrm{P}<0.01\right)$, which accounted for $22.3 \%$ of the variance associated with predicting residual sequelae. The most predictive variable was Full Scale IQ during initial hospital admission $\left(F_{1,108}=10.89 ; \quad P<0.01\right)$ followed by number of minutes of unconsciousness $\left(F_{1,108}=2.98\right.$; $P<0.10$ ). The remaining variables did not contribute significantly to the regression analysis.

School progress (Table 8) defined as normal advancement, grade failure, or placement in special class, also reflects premorbid factors such as inherent learning ability, environmental opportunities, and previous level of school achievement. For the older group, nine of the 13 children who failed or withdrew from school after successive failures had no premorbid history of school failure. Most of the younger children had not yet attended school at the time of head injury, but $25.7 \%$ subsequent to head injury either failed an elementary grade or were placed in a remedial/slow learner class.

Table 8 Educational progress

\begin{tabular}{lcll}
\hline & Younger & Older & Total \\
\hline $\begin{array}{l}\text { Normal } \\
\text { Failed grade/still in }\end{array}$ & $58(74.3 \%)$ & $26(66.7 \%)$ & $84(71.8 \%)$ \\
normal stream & $12(15.4 \%)$ & $7(17.9 \%)$ & $19(16.2 \%)$ \\
$\begin{array}{l}\text { Special/remedial classes } \\
\text { Successive failures/no }\end{array}$ & $8(10.3 \%)$ & $1(2.6 \%)$ & $9(7.7 \%)$ \\
longer in school & & $5(12.8 \%)$ & $5(4.3 \%)$ \\
\hline
\end{tabular}

EEG FINDINGS

Table 9 summarises the distribution of EEG ratings for the younger (39) and older (77) head-injured cohort groups for all EEG recordings. The figures in parentheses represent the ratings in percentages assigned to the original sample (128 in the younger and 100 in the older group). The differences in ratings between the original groups and their respective cohorts were minimal, with cohort groups exhibiting slightly less EEG abnormalities. Table 9 also indicates that with time there was a decrease in the number and shift downwards in the rating magnitude of abnormal EEG. With respect to the consistency of these ratings over the successive examinations, only 17 out of 688 ratings changed from normal or equivocal (1 or 1.5$)$ to abnormal $(2,3)$. Only one subject went from 1.5 to 3 , the remaining 16 changed from 1 to 2 or 1.5 to 2 . Thus, these rating schema provided a stable measure of EEG recovery, in that individual fluctuations from normal to abnormal were minimal.

For the purposes of younger and older group comparisons, the equivocal and normal ratings $(1,1.5)$ were combined into one category while the abnormal ratings $(2,3,4)$ were combined into another. During initial hospital admission, the presence of EEG abnormality was identical for the younger $(64.5 \%)$ and older $(65.8 \%)$ group. However, over the subsequent recordings the older group's ratings of abnormality decreased more rapidly than 
Table 9 EEG global ratings for younger $(n=77)$ and older $(n=39)$ cohorts (in percentages)

\begin{tabular}{|c|c|c|c|c|c|c|c|c|c|c|c|c|}
\hline \multirow[b]{2}{*}{ Ratings } & \multicolumn{2}{|l|}{ Initial } & \multicolumn{2}{|c|}{ One year after } & \multicolumn{2}{|c|}{ Two years after } & \multicolumn{2}{|c|}{ Three years after } & \multicolumn{2}{|c|}{ Four years after } & \multicolumn{2}{|c|}{ Five years after } \\
\hline & Younger & Older & Younger & Older & Younger & Older & Younger & Older & Younger & Older & Younger & Older \\
\hline 1 & $25(22)^{*}$ & $20(17)^{*}$ & 31 & 49 & 42 & 59 & 53 & 79 & 56 & 84 & 74 & 87 \\
\hline 12 & $12(15)$ & $16(11)$ & 21 & 26 & 26 & 28 & 19 & 13 & 19 & 8 & 10 & 8 \\
\hline 2 & $45(42)$ & $44(45)$ & 43 & 23 & 28 & 10 & 25 & 8 & 21 & 8 & 13 & 5 \\
\hline 3 & $17(20)$ & $18(25)$ & 5 & 2 & 4 & 3 & 3 & 0 & 4 & 0 & 3 & 0 \\
\hline 4 & 1(1) & $2(2)$ & 0 & 0 & 0 & 0 & 0 & 0 & 0 & 0 & 0 & 0 \\
\hline
\end{tabular}

* Percentages in parentheses based on total numbers included in younger $(n=128)$ and older $(n=100)$ groups.

the younger group. Both groups did show a strikingly significant decline in the number of abnormal EEG from the initial examination to the fifth follow-up $\left(\chi^{2}=35.2, \quad \mathrm{P}<0.001\right.$ for the younger; $\chi^{2}=25.0$, $\mathrm{P}<0.001$ for the older). Furthermore, the older stabilises three years after trauma while improvement is still evident in the younger group five years after trauma.

The specific kinds of EEG abnormalities accounting for global rating of 1.5 or more in the initial EEG included diffuse and focal types, both paroxysmal and continuous. The most common abnormality initially was some degree of diffuse slow activity $(41 \%$ and $45 \%$ for the younger and older groups respectively) while asymmetry of background activity was almost as common $(37 \%$ and $35 \%)$. Focal slow activity was found in $16 \%$ and $18 \%$, focal spike discharges in $5 \%$ and $13 \%$, and spike and wave bursts in $4 \%$ and $2 \%$ of the initial EEG from younger and older groups respectively.

Over the five year period of reassessment, all of these abnormalities tended to disappear, although not at the same rates. Generalised slow activity and focal spikes persisted longer than any other kind of abnormality, particularly in the younger group. The incidence of focal spike abnormalities actually increased from the first year of follow-up to the fourth year in the younger cohort (from $9 \%$ to approximately $18 \%$ ).

No specific EEG abnormality showed any particular correlation with seizures. The incidence of seizures was low in this study (even in the presence of focal or generalised paroxysmal abnormalities in the EEG) both on hospitalisation and over the following five years. Only five children (three younger, two older) had seizures during their hospitalisation, and none of these had any history of seizure recurrence in the next five years. Nine children (six younger, three older) had seizures during the five year followup, but none had any recurrence after the fourth follow-up.

With respect to prediction of abnormal EEG, a discriminant analysis was done using the eight initial trauma variables with group membership defined as the presence (2-3) or absence of an abnormal EEG (1-1.5). The results are summarised in Table 5. The overall correct classification was $79.3 \%$.

\section{OVERALL ASSESSMENT OF RESIDUAL HEAD INJURY}

EFFECTS

For all intents and purposes, the younger and older groups were equivalent with respect to recovery, and in order to evaluate further the long-term residual effects of head injuries, the two groups were combined. Although the three areas were qualitatively different in terms of assessment-different examiners, independent examinations, different conceptual models and derivation of a positive sign index - the examination of positive signs by area and by child allows for further analysis. These data are summarised in Table 10 for the incidence of positive

Table 10 Overall assessment of head injury effects

\begin{tabular}{lll}
\hline Area/subject & \multicolumn{2}{c}{ Positive signs of impairment } \\
& Number & $\%$ \\
\hline By area & & \\
Neuropsychological & 27 & 23.0 \\
EEG & 14 & 12.0 \\
Neurological & 28 & 23.9 \\
By subject & & \\
Number exhibiting & 51 & 43.6 \\
One area only & 35 & 29.9 \\
Two areas & 14 & 12.0 \\
Three areas & 2 & 1.7 \\
\hline
\end{tabular}

signs found in each area. Of the 14 children with abnormal EEGs, nine $(64.3 \%)$ exhibited positive signs in either both or one of the other areas. For neuropsychological positive signs, 13 of the 27 children $(48.1 \%)$ exhibited positive signs in either both or one of the other areas. For the neurological sequelae reported, 12 of the 28 children $(42.9 \%)$ had other residual signs.

These clinical findings of residual effects related to head injury may be cross-validated with respect to their magnitude and social ramifications when combined with school performance. For the 33 
children in both groups with school failure, remedial class placement, or both, $15(45.5 \%)$ had neurological sequelae, $13(39.4 \%)$ had residual neuropsychclogical effects, and two $(6.1 \%)$ had abnormal EEGs on the fifth follow-up. Overall, $66.7 \%$ of this group had recorded residual effects in at least one area on the fifth follow-up.

\section{Discussion}

The findings for the three areas indicated that there were immediate and very pronounced effects for both the younger and older groups. With time these effects decreased markedly, so that by the fifth follow-up a majority of the children were well or recovered. The EEG ratings had the most rapid recovery of the three measures for both groups. However, on the fifth re-examination there was still evidence of EEG abnormality in $15 \%$ of the younger group and $5 \%$ of the older group. Whether this differential incidence of abnormality was related to age or head injury could not be determined. In terms of a clinical instrument for evaluating and monitoring head injury, the EEG was shown to be very stable in terms of return to normal, and often associated with other positive clinical findings. These findings support the importance of EEG for monitoring the recovery pattern in head injuries (Kubala and Kellaway, 1967; Rodin, 1967).

The neuropsychological findings indicated slower recovery rate than the EEG but by the fifth trial the number of significant differences between the headinjured children and their matched controls had reduced markedly. By the fifth follow-up, $23.7 \%$ of the head-injured children still exhibited impaired neuropsychological performance on the test battery, these being more or less equally distributed between the younger and older groups $(25.3 \%$ and $20.5 \%$ of the respective groups). Moreover, Full Scale IQ was predictive of potential residual sequelae. Secondly, this variable should increase discernibly with time if reconstitution is occurring. This relationship of increase in operational intelligence as a measure of recovery rate is in agreement with other studies (Brink et al., 1970; Black et al., 1971; Mandleberg and Brooks, 1975; Najenson et al., 1975).

Of the three areas, the neurological area was least likely to show change, in that $38 \%$ of the younger and $31 \%$ of the older groups still exhibited residual sequelae on the fifth follow-up. This reported persistence of neurological deficit has been reported by others (Black et al., 1971) but is confounded by different evaluation procedures-presence/absence criteria versus an improvement/change measure (Brink et al., 1970). In this study the child must have had recorded sequelae on both the fourth and fifth follow-up examination for the term residual to be applied; residual sequelae in the groups for subsequent discussion is $23.9 \%$.

With respect to consistency and the generalisation of these residual effects over the examination areas and their direct relationship to head injury, the residual impairment found in the children is worthy of further discussion. For those children exhibiting residual signs in two or three areas $(13.7 \%)$, the conclusions regarding impairment due to head injury are firm. However, for the children with residual signs in only one area $(29.9 \%)$, the direct relationship to head injury may be equivocal. But a strong argument for the association of head injury and subsequent impairment of neuropsychological functioning is suggested by the striking difference in incidence of impairment between the head-injured group and their matched controls. For the neurological examination, the incidence of $23.9 \%$ suggests an abnormal population. For the EEG ratings, only five of the 14 abnormal ratings were not associated with residual signs in the other two areas. Thus, these results indicated that: (1) the long-term effects of head injury may be qualitatively different for some children in terms of the area affected; and (2) in some? children these effects are generalised.

With respect to the reconstitution process the question arises as to whether it is a function of the severity and type of head injury, individual differences in disposition, subsequent environment or an interaction of these variables. The prediction analyses indicated that for the neuropsychological and the neurological areas, the trauma variables subsequent to head injury form a basis for prediction, but alone did not account for the majority of the variance (for example, for the neurological regression analysis of sequelae, $22.7 \%$ of the total variance was accounted for). Similar findings with respect to premorbid and trauma variables being used to predict residual effects (Brink et al., 1970; Black et al., 1971) have shown a relationship between these variables and outcome. However, the reported relationships are not powerful with respect to ultimate prediction. Thus, these results indicated that although these clinical assessments are useful in prognosis, other variables may exist which might allow for more precise or accurate prediction.

This research was supported by Grant 609-7-138, National Health Grants, Ottawa, Canada. The authors wish to express their appreciation to Dr R. Paris for examining the head-injured children, to Dr J. Poole, B. Shuman, and H. Krivel for making available the control groups, to Dr G. C. Robinson, Dr G. B. Thompson, Dr D. Crockett, Mrs B. Simpson, Mrs P. Rintoul, and E. Holmes for their 
invaluable assistance, to the Vancouver General Hospital and the Health Sciences Centre for providing the necessary research facilities, and to the Computing Centre, University of British Columbia.

\section{References}

Benton, A. (1959). Left Discrimination and Finger Localization: Development and Pathology. Hoeber: New York.

Black, P., Blumer, D., Wellner, A. M., and Walker, A. E. (1971). The head-injured child: time-course of recovery, with implications for rehabilitation. In Head Injuries, Proceedings of an International Symposium. Churchill Livingstone: Edinburgh and London.

Brink, J. D., Garrett, A. L., Hale, W. R., Woo-Sam, J., and Nickel, V. L. (1970). Recovery of motor and intellectual function in children sustaining severe head injuries. Developmental Medicine and Child Neurology, 12, 565-571.

Klonoff, H., Robinson, G. C., and Thompson, G. (1969). Acute and chronic brain syndromes in children. Developmental Medicine and Child Neurology, 11, 198-213.

Klonoff, H. (1971). Head injuries in children: predisposing factors, accident conditions, accident proneness and sequelae. American Journal of Public Health, 61, 2405-2417.

Klonoff, H., and Low, M. (1974). Disordered brain function in young children and early adolescents: neuropsychological and electroencephalographic correlates. In Clinical Neuropsychology: Current Status and Applications. Edited by R. M. Reitan, and L. A. Davison. John Wiley and Sons: New York.
Klonoff, H., and Paris, R. (1974). Immediate, short-term and residual effects of acute head injuries in children: neuropsychological and neurological correlates. In Clinical Neuropsychology: Current Status and Applications. Edited by R. M. Reitan, and L. A. Davison. John Wiley and Sons: New York.

Knights, R. M. (1966). Normative data on tests for evaluating brain damage in children from 5 to 14 years of age. Research Bulletin, No. 20. University of Western Ontario: London, Ontario.

Kubala, M. J., and Kellaway, P. (1967). Cerebral concussion in children: a longitudinal EEG profile. Electroencephalography and Clinical Neurophysiology, $23,82$.

Lishman, W. A. (1973). The psychiatric sequelae of head injury: a review. Psychological Medicine, 3, 304-318.

Mandleberg, I. A., and Brooks, D. N. (1975). Cognitive recovery after head injury. Journal of Neurology, Neurosurgery, and Psychiatry, 38, 1121-1126.

Najenson, T., Groswasser, Z., Stern, M., Schechter, I., Daviv, D., Barghaus, N., and Mendleson, L. (1975). Prognostic factors in rehabilitation after severe head injury. Scandinavian Journal of Rehabilitation Medicine, 7, 101-105.

Reitan, R. M. (1974). Psychological effects of cerebral lesions in children of early school age. In Clinical Neuropsychology: Current Status and Applications. Edited by R. M. Reitan, and L. A. Davison. John Wiley and Sons: New York.

Rodin, E. A. (1967). Contribution of the EEG to prognosis after head injury. Diseases of the Nervous System, 28, 595-601. 